\title{
Research
}

\section{Building managed primary care practice networks to deliver better clinical care:}

\author{
a qualitative semi-structured interview study
}

\begin{abstract}
Background

Primary care practices are increasingly working in larger groups. In 2009, all 36 primary care practices in the London borough of Tower Hamlets were grouped geographically into eight managed practice networks to improve the quality of care they delivered. Quantitative evaluation has shown improved clinical outcomes.

\section{Aim}

To provide insight into the process of network implementation, including the aims, facilitating factors, and barriers, from both the clinical and managerial perspectives.
\end{abstract}

\section{Design and setting}

A qualitative study of network implementation in the London borough of Tower Hamlets, which serves a socially disadvantaged and ethnically diverse population.

\section{Method}

Nineteen semi-structured interviews were carried out with doctors, nurses, and managers, and were informed by existing literature on integrated care and GP networks. Interviews were recorded and transcribed, and thematic analysis used to analyse emerging themes.

\section{Results}

Interviewees agreed that networks improved clinical care and reduced variation in practice performance. Network implementation was facilitated by the balance struck between 'a given structure' and network autonomy to adopt local solutions. Improved use of data, including patient recall and peer performance indicators, were viewed as critical key factors. Targeted investment provided the necessary resources to achieve this. Barriers to implementing networks included differences in practice culture, a reluctance to share data, and increased workload.

\section{Conclusion}

Commissioners and providers were positive about the implementation of GP networks as a way to improve the quality of clinical care in Tower Hamlets. The issues that arose may be of relevance to other areas implementing similar quality improvement programmes at scale.

\section{Keywords}

federation; general practice; integration; networks; primary health care; qualitative research; quality improvement; UK.

\section{INTRODUCTION}

Effective primary care is a prerequisite of well-functioning healthcare systems. ${ }^{1-3}$ An ageing, multimorbid population places increasing demands on an already resource-constrained health system. ${ }^{3,4}$ Federated or networked general practices are seen as potentially providing better health gain than individual practices, and to coordinate better with community and hospital services. ${ }^{5}$ Terms and models used include federations, networks, alliances, collaborations, joint ventures, and consortia. ${ }^{6-8}$ However, there remains uncertainty about their purpose and impact. A recent Nuffield Trust review ${ }^{9}$ describes the contextual factors such as efficiencies of scale driving larger-scale collaboration, but confirms the paucity of data on evaluation.

\section{NHS primary care reform}

There has been a rapid transition towards larger group practices in the UK, reducing single-handed practices by 35\% between 2004 and 2009. ${ }^{10}$ In 2006, recommendations for primary care in London included the creation of polyclinics with multiple providers serving populations of around $50000 .{ }^{11}$ GPs felt that these proposals eroded key provider attributes such as access, choice, and continuity of care, and in response the Royal College of General Practitioners published recommendations supporting federated working, emphasising the need for collaboration rather than amalgamation of practices. ${ }^{12,13}$ Since then,

J Pawa, MD, CCFP, public health and preventive medicine resident physician, University of Toronto, Toronto, Ontario, Canada. J Robson, MD, FRCGP, GP, reader in primary care; S Hull, MRCP, FRCGP GP, reader in primary care, Centre for Primary Care and Public Health, Queen Mary University of London, London, UK

\section{Address for correspondence}

Jasmine Pawa, c/o PHPM Chief Residents,

155 College Street, 5th Floor, University of Toronto, multiple initiatives testing new models of care have been piloted, including 16 integrated care pilots in 2009,4 14 integrated care pioneers in 2013, and in 2015, 50 vanguard sites all with a common theme of focusing on various ways of improving integration. ${ }^{14,15}$ Drawing coherent policy lessons from these diverse developments has been challenging ${ }^{16}$ due to the diversity of the models, limited rigorous evaluation, frequency of changes and new initiatives, difficulties both measuring outcomes and attributing causality to these models, and finally, the complexity of the changes.

\section{Tower Hamlets practice networks}

Served by 36 general practices, the borough of Tower Hamlets has an ethnically diverse and disadvantaged population of 284000 including the largest Bangladeshi community in England, ${ }^{17}$ high population turnover, ${ }^{18}$ and the highest proportion of children (59\%) and older people (53\%) in income-deprived families in the UK. ${ }^{19}$

In 2007, the primary care trust (PCT), now the clinical commissioning group (CCG), decided to invest available NHS funding growth into primary care. ${ }^{20}$ A primary care investment plan developed four extended clinical packages for diabetes, chronic obstructive pulmonary disease, cardiovascular disease, and childhood immunisation, with an associated increase in primary care spend. The topics chosen were considered to be evidence based and ameliorable within the context of the

Toronto, Ontario, M5T 3M7, Canada.

E-mail: pawadualberta.ca

Submitted: 8 January 2017; Editor's response: 20 February 2017; final acceptance: 25 April 2017. CBritish Journal of General Practice This is the full-length article (published online 12 Sep 2017) of an abridged version published in print. Cite this version as: $\mathrm{Br} J$ Gen Pract 2017; DOI: https://doi.org/10.3399/bjgp17X692597 


\section{How this fits in}

General practices in the UK are increasingly working in groups, but literature on implementation or evaluation of this process is limited. Tower Hamlets in London has demonstrated success in quality improvement using geographically-based clinical networks. Key factors of this success include alignment of clinical and managerial priorities, strong leadership, a data-driven approach to performance, and flexibility towards local solutions. The networks were seen as sustainable and laid the groundwork for a subsequent multisectoral provider partnership of all practices in collaboration with local authority, mental health services, and secondary care.

programme demonstrating tangible impact within 3 years. The clinical improvement packages were designed by both clinicians and administrators to match best practice within resource constraints. Activities included multidisciplinary team meetings, care plans, medication reviews, call/recall coordination and group training, and the use of common data entry templates enabling feedback of identifiable practice performance across the organisation combined with financial incentives for achieving agreed targets.

Eight geographical practice networks (each with four to five GP practices) were created to deliver these care packages, each serving populations of 30000-50 000 . Funding for additional services and achievement of clinical targets was directed at the network rather than at individual practices. Approximately $€ 1.2$ million was provided for network management including $£ 150000$ per network to fund manager, recall coordinator, board representatives, and clinical lead roles. Additional financial incentives for achieving performance targets were paid, with $70 \%$ paid upfront and $30 \%$ contingent on performance. ${ }^{20,21}$

The network structure sought to encourage peer-to-peer learning, scrutiny, and support for quality improvement. Information technology (IT) was developed using an existing IT infrastructure. Standard data entry templates and near real-time network dashboards were devised to visualise both individual trends in practice performance and comparison with all other practices. Near real-time network dashboards provide visual summaries of how a practice is performing on relevant care package metrics compared to the other practices and networks. A red, amber, and green colour scheme was used as were trend charts and funnel plots to describe performance and variation. Patient recall systems were also improved. Multidisciplinary team meetings (MDTs) provided feedback, review of performance, and a forum for case-based clinical discussion and education.

Four quantitative studies have been published which show significant improvement in Tower Hamlets as a result of these programmes, including rapid achievement of $95 \%$ population coverage for measles, mumps, and rubella immunisation, and some of the best and fastest-improving cardiovascular measures in London and England. ${ }^{22-25}$ In 2015, Tower Hamlets ranked first, second, or third among the 211 CCGs in England in 10 of the total 65 clinical indicators in the national Quality and Outcomes Framework (QOF).

This qualitative study considers participants' views on organisational aims and provider experience during network implementation to provide insight into this organisational change. The results of these interviews are described in relation to existing primary care and organisational change literature and the policy environment.

The study aimed to investigate the expressed aims of establishing GP networks, what facilitated their implementation, the barriers encountered and how they were overcome, and how clinicians and managers defined success.

\section{METHOD}

\section{Data collection}

A topic guide was developed based on existing network and integrated care literature (Appendix 1). This was piloted with one to two other individuals with experience in conducting interviews on the topic of integrated care. Staff from five out of the eight networks were chosen to represent geographic diversity and interviewees were purposefully selected for their network experience, with further contacts suggested by interviewees. Nineteen semistructured interviews (typically 1 hour long) were conducted in July and August 2015 with practice managers or reception staff $(n=3)$, network manager/coordinator $(n=2)$, GPs $(n=8)$, nurses or healthcare assistants (HCAs) $(n=3)$, and PCT/CCG managers $(n=3)$. 'A' refers to those at practice level (receptionist or practice manager) or network level (network coordinator or network manager), 'C' refers to commissioning staff at the PCT/ CCG, 'D' refers to GPs, and ' $N$ ' refers to 
nurses/HCAs. Consent was obtained and all interviews were recorded and transcribed. Grey literature was examined including consulting company reports, minutes, and documents pertaining to the networks.

\section{Thematic analysis}

Thematic analysis was used to synthesise results. ${ }^{26,27}$ All interviews were conducted and coded by the first author. ${ }^{28} \mathrm{All}$ transcripts were systematically coded using NVivo (version 10). ${ }^{26,29}$ Themes were organised through discussion, summary tables, and mind-maps. ${ }^{30}$ Information was triangulated between sources and data saturation was sought. Themes were reviewed with two experienced GPs who had a broad understanding of the networks.

\section{RESULTS}

The four main themes that emerged from the interviews are summarised in Box 1.

\section{What are the networks for?}

Improving quality of care for patients. When asked about network aims, nearly all interviewees highlighted improving quality of clinical care and patient outcomes. This sense of shared purpose was a key element, irrespective of job role or position:

We're all here for the same reason, we need to care about the patients.' (N2)

Reducing variation in performance. Reduction in variation of practice performance was identified as a key aim. Some mentioned the importance of choosing clinical conditions that were

\section{Box 1. Summary of key themes from the interviews}

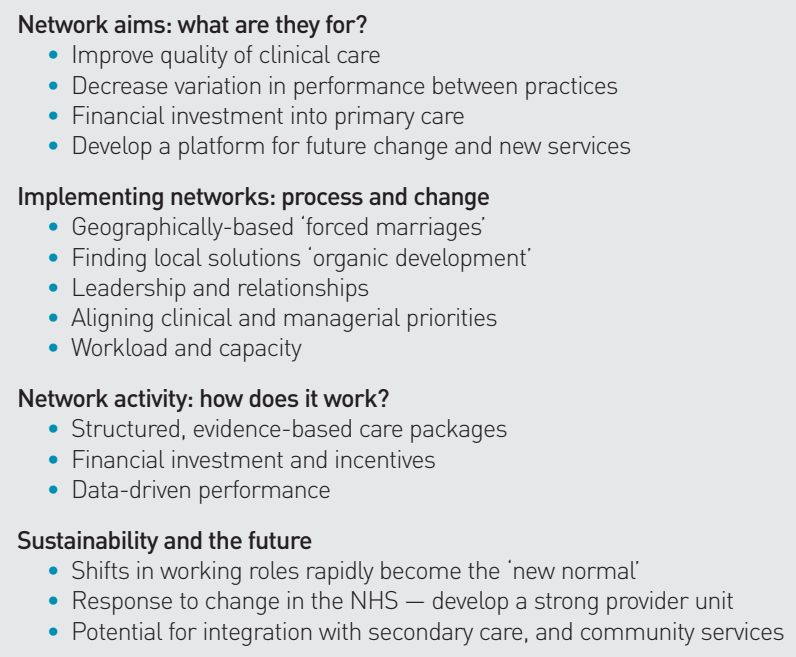

ameliorable to primary care intervention.

Quality improvement was clearly defined; for example, with respect to immunisations, this involved taking an effective intervention and applying it to all population segments, including those that are harder to reach:

'The networks was an approach to reducing that variation in quality, raising standards. (C1)

Investing financially into primary care. Approximately half of interviewees commented on the importance of the PCT decision to invest financially in primary care, and the need to protect this in the future:

Unless we were very clear strategically about the future of primary care services in this very deprived area of London ... there was a concern that the brand new shiny hospital ... would suck patients in.' (C3)

Developing primary care services with an eye to future change. PCT staff were more likely to view the network aims as a step to further development:

'The networks just became a means to an end and I think having a stronger provider of primary care was effectively what we felt was needed.' (C3)

Clinical staff were more likely to comment on the tension between providing advantages of scale while maintaining local relationships and the access provided by smaller and more local practices:

If you create a super practice then it's too big and then you lose continuity of care and ... you don't get those working relationships.' (D2)

Several interviewees highlighted that networks presented opportunities for collaboration and learning new ways of working from other practices:

We used to be very isolated, we hardly ever came out of the practices and that's not the case any more. So the network brings stuff into us and brings us out to stuff.' (D7)

\section{Implementing networks}

Geographically-based: promoting equity. Geographically-determined networks ensured they served a defined population, aligned to local area boundaries with potential links to social services. Several doctors noted that if practices had chosen which network they could join this might lead to inequity: 
'Feeling that if you let all the high-flying practices work together, you'd get an inequality which ran against the ethos of providing uniform primary care...' (D4)

Practices differed by patient demography and practice characteristics, including performance variation, culture, and appetite for financial and organisational risk, and almost every interviewee commented on the challenge this presented:

'Even when they've been down the road from each other, [practices] have never actually met, let alone been held formally jointly accountable for delivery of something that had cash attached ... so there was a huge amount of work to do developing relationships ... and setting out the rules of engagement.'(C1)

These differences led to early resistance by some who were worried about being 'dragged down' (D3) by another practice's poor performance, which might impact financial incentives. Some were concerned about the external scrutiny of their clinical work, confidentiality around data sharing, the additional workload, and a lack of evidence of benefit.

Several contextual factors helped address these challenges. Before the networks were formed, several poorly performing practices had had a formal performance review and a few had their contracts ended. ${ }^{21}$ Organisational consultancy provided by the PCT included discussion of different approaches to clinical improvement, including financial incentives and resourcing practices which had difficulty meeting targets. ${ }^{31}$ However, the challenges presented by differences in practice culture remained of concern to some practices, but were tolerated for the sake of perceived gains:

We haven't really solved this; I think we've accepted unspokenly, that this is a problem that we won't be able to solve. '(D1)

Finding local solutions. Aspects of the networks, such as the geographic basis, network level incentives, and performancesharing dashboards were non-negotiable, but there was considerable local flexibility over implementation.

Networks differed in how they approached governance, meetings, staffing, community involvement, and financial decisions. The key lesson was to leave room for flexibility, innovation, and local decisions within explicit parameters:
We needed to find what worked for our individual teams and practice in a way that they work rather than finding a blueprint that could just be rolled out.' (N1)

Leadership matters and relationships. Interviewees frequently spoke of strong and flexible leadership by the PCT and senior GPs, and the importance of quick wins: visible improvements that occurred very quickly and could be used to build morale and momentum in order to demonstrate immediate system benefits to practitioners and the PCT board.

Contextual circumstances contributed to making the environment conducive to networks, including a history of practice data sharing, and a positive relationship between commissioners and providers:

'There was a lot of trust between us in what we were trying to achieve.' (C1)

Two interviewees commented that Tower Hamlets PCT was more positive to GPs than some other areas as it has less policing functions than elsewhere:

It has a really good tradition of people working together... I really would think twice about going to another area again. ' (C1)

Aligning clinical and managerial priorities. The alignment of clinical and managerial priorities frequently emerged as a theme.

This facilitated network activity, such as sharing estate, staff, ideas, physical resources, and services. Pre-existing conditions such as good working relationships and advanced use of information technology were key to this, but leadership was required to recognise and grasp the emerging opportunities:

You sometimes get opportunities to do things because you have an alignment across organisations ... what we were able to do was try and use that to leverage some collective action.' (C3)

'There was a joint vision really between the senior managers and the senior clinicians in Tower Hamlets, which I think paved the way for a relatively radical approach to reforming the way that primary care was commissioned. '(A6)

This was equally important at network level where the benefits of informal peer-topeer conversations and relationship building across practices emerged. Interviewees commented they were more likely to pick up 


\begin{tabular}{|c|c|c|c|c|c|c|c|c|c|c|c|c|c|c|}
\hline & Criteria & Metric & Units & Target & April & May & June & July & Aug & Sept & Oct & $\begin{array}{l}\text { This } \\
\text { Month }\end{array}$ & $\begin{array}{l}\text { This } \\
\text { Month }\end{array}$ & $\begin{array}{l}\text { RAG } \\
\text { Status }\end{array}$ \\
\hline \multirow{6}{*}{5.1} & \multirow{6}{*}{$\begin{array}{l}\text { Increase in recorded } \\
\text { prevalence }\end{array}$} & $\%$ Increase in COPD register & \multirow{6}{*}{$\%$} & & & & & & & & & & & \\
\hline & & $\begin{array}{l}\text { confirmed by spirometry in } \\
\text { the last } 12 \text { months }\end{array}$ & & 10 & 0.0 & 1.0 & 2.5 & 2.5 & 2.8 & 1.5 & 2.3 & 2.3 & 1.5 & RED \\
\hline & & Practice A & & 10 & 0.0 & 0.0 & 0.0 & 0.0 & 0.0 & 0.9 & 1.79 & & & \\
\hline & & Practice B & & 10 & 0.0 & 0.0 & 2.2 & 2.2 & 2.79 & 0.6 & 1.68 & & & \\
\hline & & Practice C & & 10 & 0.0 & 2.8 & 6.0 & 2.8 & 2.78 & -2.8 & -2.78 & & & \\
\hline & & Practice D & & 10 & 0.0 & 4.1 & 5.5 & 6.9 & 6.85 & 6.9 & 6.85 & & & \\
\hline \multirow{6}{*}{5.2} & \multirow{6}{*}{$\begin{array}{l}\text { Review of COPD patient } \\
\text { with self-management } \\
\text { action plan (frequency } \\
\text { is severity dependent) }\end{array}$} & All patients with COPD with & \multirow{6}{*}{$\%$} & & & & & & & & & & & \\
\hline & & $\begin{array}{c}\text { annual review and } \\
\text { self-management plan }\end{array}$ & & 85 & 63.8 & 62.5 & 62.3 & 67.1 & 68.3 & 71.6 & 74.3 & 74.3 & 71.6 & AMBER \\
\hline & & Practice A & & 85 & 53.7 & 51.9 & 55.6 & 53.7 & 53.70 & 56.5 & 69.72 & & & \\
\hline & & Practice B & & 85 & 59.1 & 57.4 & 56.6 & 58.0 & 58.32 & 63.1 & 64.3 & & & \\
\hline & & Practice $\mathrm{C}$ & & 85 & 41.7 & 35.1 & 37.0 & 66.7 & 66.7 & 31.4 & 45.7 & & & \\
\hline & & Practice D & & 85 & 76.7 & 76.6 & 73.7 & 85.6 & 86.7 & 89.84 & 90.0 & & & \\
\hline & \multirow{6}{*}{$\begin{array}{l}\text { COPD patients with } \\
\text { MRC score } \geq 3 \\
\text { referred to pulmonary } \\
\text { rehabilitation (ever) }\end{array}$} & All patients with COPD and a & & & & & & & & & & & & \\
\hline & & $\begin{array}{l}\text { FEV1 } \%<50 \text { (ever) referred to } \\
\text { pulmonary rehabilitation (ever) }\end{array}$ & $\%$ & 75 & 56.5 & 58.7 & 59.2 & 60.3 & 65.27 & 59.5 & 53.9 & 53.9 & 59.5 & AMBER \\
\hline & & Practice A & & 75 & 71.1 & 76.9 & 76.2 & 75.6 & 76.19 & 72.7 & 65.33 & & & \\
\hline & & Practice B & & 75 & 51.6 & 52.4 & 52.4 & 51.6 & 51.56 & 50.8 & 46.43 & & & \\
\hline & & Practice C & & 75 & 83.3 & 83.3 & 83.3 & 83.3 & 83.3 & 100.0 & 40.00 & & & \\
\hline & & Practice D & & 75 & 33.3 & 33.3 & 36.8 & 50.0 & 50.0 & 50.0 & 58.54 & & & \\
\hline
\end{tabular}

Figure 1. Example of a red, amber, green (RAG) chart. This figure provides an example of some of the metrics that were used for Chronic Obstructive Pulmonary Disease (COPD) and shows how practice performance was compared at a glance. This was shared between practices with the practices named. the phone, email, or visit another practice after networks were implemented.

Network MDTs were considered effective. They comprised nurses, GPs, a consultant, and community staff, and provided a forum to work together on clinical tasks. One nurse stated:

'MDTs we do for diabetes are the best thing ever really.' (N1)

\section{The MDTs were described as an:}

Opportunity to meet with so many clinicians that are involved in the patient's journey ... I think the key thing is the case discussions that we have with an expert there, for the consultant to be there really helps.' (N2)

MDTs worked most effectively and consistently for those with diabetes, with difficulty engaging consultants to attend for other specialties.

Workload and capacity. Almost all interviewees discussed concerns about capacity and workload:

'Everyone feels they're just completely, almost overwhelmed by the volume of work.' (D2)
While it was helpful to have funding for backfilling positions, locums were viewed as unsatisfactory and sometimes network clinical lead positions were unfilled. There was a sense that network development was hard but valuable and worthwhile work. Some felt that it built too quickly while others felt that the sense of momentum was helpful. There was agreement that a sense of ownership over the work of network development and the flexibility around this, was helpful.

\section{Network activity}

Structured care packages with financial incentives. Almost all interviewees highlighted the central role of key performance indicators linked to financial incentives. Many commented that the money invested was a key reason the networks have worked. As one GP commented:

'It shows like anything, if you incentivise people they'll do something ... if the outcomes improve and the general health of the population improves, I think that's a good thing.' (D1)

Overall, performance measures and incentives were viewed as key to network success: 
Money talks and people will always respond to money ... being rewarded for actually doing the work that they're doing. Because it is a lot of work.' (N2)

The alignment of incentives was deliberate, with many network targets being further extensions of those already supported in the national QOF scheme.

Data-driven performance. A recurrent theme was the value provided by structure and standardisation:

$\therefore$ needs of the patients are being met better than they ever were before because it's more structured and it's more obvious when patients are not attending. '(N2)

Interviewees valued standardised data entry templates during consultations, as well as standardised searches, which streamlined call and recall.

Every interviewee spoke about the use of data and IT, and it was commonly identified as indispensable to the networks. There is a long history of practice data sharing in Tower Hamlets, led by the Clinical Effectiveness Group ${ }^{32}$ la multidisciplinary team of GP clinical leads, in-practice facilitators, data analysts and researchers covering three PCTs) which has driven local quality initiatives since the 1990s. The Clinical Effectiveness Group provided networks with clinical guidelines, data entry templates, standardised searches, performance dashboards, and educational meetings, all supported by in-practice facilitators. Funded by the PCT and with senior GP leadership, the Clinical Effectiveness Group is able to act as a trusted intermediary between practices, networks, and the PCT.

Monthly performance metrics for each care package were shared across the networks, with access to information in an easy to interpret format; usually as bar or RAG (red, amber, green) charts (for an example see Figure 1), allowing each practice to get a sense of its performance compared with others:

'So if they can achieve it why can't we achieve it? It's a little bit about the competitive aspect but also the aspect of "well, what are they doing that's working and what; can we maybe try that approach?" So we are all aware of the RAG charts now which we didn't have a clue about before.' (N2)

The dashboards include all patient outcomes without 'exception reporting' to maintain a consistent and simple reporting denominator without any exceptions. Some interviewees commented that this avoided any excuses for poor performance:

Because often the people they were exception reporting were the people you most need to get to. '(C1)

This was not to say that data use was unchallenged. One practice chose not to share data for several years due to concerns about confidentiality, but overall, data sharing and access to real-time clinical data were considered key enablers to network implementation:

'Having that transparency of information and clinician-to-clinician conversation around quality rather than a commissionerto-provider conversation shifted people's approaches and how they reviewed their processes and practices.' (C1)

\section{Sustainability and the future}

Shifts in working roles rapidly becoming the 'new normal'. All interviewees assessed the networks as a positive and sustainable development that had become a new normal':

As soon as more or less everybody does it, it becomes entirely acceptable to everyone to do it. Whereas previously it's ... "do I have to do that?"' (D4)

'The other thing l'd say is success breeds success. So because we became recognised as doing the right thing we won some awards ... so there was a bit of positive psychology I think in all of this as well.' (C3)

Response to change in the NHS: developing a strong provider unit. Most interviewees had concerns about the NHS in a time of instability and marketisation impacting on continuity and fragmentation.

Larger GP groups were viewed as advantageous:

Everybody is developing some sort of care group, provider group to cushion themselves against privatisation.' (D4)

Potential for integration with secondary care and community services. In 2015, the natural extension of networks was the formation of the federated GP Care Group, a provider group linking the 36 practices. The federated Care Group was formed to create a single provider organisation. The networks remained as delivery structures 


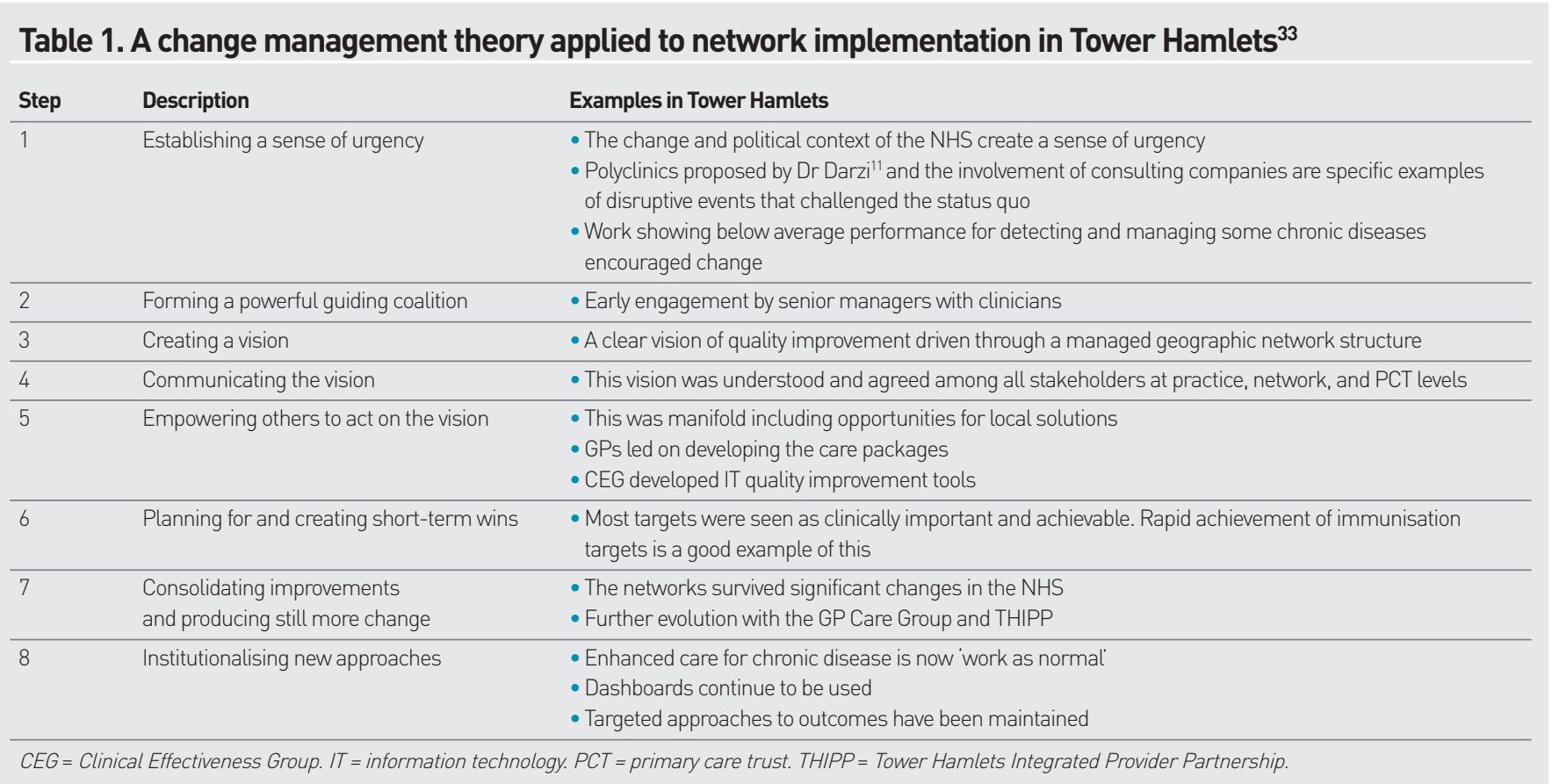

for the new federation.

The Care Group is also a member of a multispecialty provider group: Tower Hamlets Integrated Provider Partnership (THIPP), which includes Tower Hamlets Council (local authority), Barts Health (secondary care), and East London Mental Health Trust) under new government arrangements for commissioning.

\section{DISCUSSION}

\section{Summary}

Interviewees considered that networks enabled more efficient working, improved clinical quality, and reduced variations in care. Difficulties in relationships between practices remained, but were offset by the benefits that networks afforded to organisational and clinical capacity. Similarly, individuals commented it was a challenge but manageable and that the change was overall beneficial. Effective use of data and flexibility in local solutions enabled early wins such as rapid improvement in immunisation rates. Continuity of leadership, facilitative working relationships, and an IT infrastructure that could be rapidly expanded to support networks were important contextual issues.

\section{Strengths and limitations}

The strengths of this study include the number of interviews conducted and the diversity of interviewees including front desk clerical staff, managers, nurses, GPs, and senior PCT leadership. Limitations include a single researcher conducting interviews and potential for recall bias as the study was conducted several years after the networks began.

The authors bring experience, prior assumptions, and perspectives from clinical work in primary care while the research design explicitly included a range of different interviewee backgrounds.

\section{Comparison with existing literature}

Conner suggested that networks need to identify their purpose, role, and outcomes in order to be successful. ${ }^{8}$ Tower Hamlets achieved this by identifying the clinical need of its local population, the added value of networks in sharing resource and ideas, and focusing consistently on clinically important measurable outcomes.

The key strategies for change management described by Kotter resonate with the network implementation in this study, as outlined in Table $1 .{ }^{33}$ The PCT made clear that the framework for implementation will include celebrating early wins', ${ }^{20}$ of which immunisation was an early example, and later success in the national QOF also demonstrated. Innovation became embedded as 'work as normal', with rapid uptake of new processes for call and recall. ${ }^{24}$

Encouraging local solutions is supported by a systematic review, emphasising that there is no 'one-size-fits-all model', with success described as dependent on top management commitment and bottom- 


\section{Funding}

Funding for interview transcription was provided by the Clinical Effectiveness Group based at Queen Mary University of London.

\section{Ethical approval}

Ethical approval for the study was obtained from the London School of Hygiene and Tropical Medicine (LSHTM) MSc Research Ethics Committee (reference: 9532).

\section{Provenance}

Freely submitted; externally peer reviewed.

\section{Competing interests}

Two collaborators also provided interviews for this study. The other authors declare no competing interests.

\section{Acknowledgements}

This work was completed as part of a Master's degree in Health Policy, Planning, and Financing la joint programme between the London School of Hygiene and Tropical Medicine and the London School of Economics and Political Science). Thanks to Bob Erens for his role as dissertation supervisor and for reviewing a draft of this work. Academic support was provided by Stefanie Ettelt and best practices for qualitative research were discussed with Meredith Hawking. Other support was provided by Rohini Mathur and Kerry Waddell. Thanks to the interviewees for their time and insight.

\section{Discuss this article}

Contribute and read comments about this article: bjgp.org/letters up approach' ${ }^{34,35}$ A qualitative study of implementing clinical governance in 12 PCTs in the early 2000s describes the use of traditional audit and incentives, with the added value of joint learning of business skills and a bottom-up approach. ${ }^{36}$ This was consistent with the current study's findings, in which PCT leadership provided management commitment but there was freedom for clinical and administrative staff to seek local solutions.

Participants recognised the value of both administrative and clinical roles, including the 'hybrid roles' of network managers and in particular the role of the Clinical Effectiveness Group and it's in-practice facilitators, that bridge the clinical and administrative divide between CCGs plans and practice delivery. ${ }^{7}$ The clinical lead roles fit with collegial self-regulation of primary care practice work, ${ }^{37}$ and confirm the added value of visiting and learning from other practices. ${ }^{38,39}$

A systematic review of health systems integration identifies 10 principles that echo the findings of this study including an identified population, structured interdisciplinary care, sufficient funding, IT-supported performance management, leadership, organisational support, and physicians in central roles. ${ }^{34}$ The findings of the current study are also consistent with literature emphasising the opportunities of routine primary care data for quality improvement, and the importance of geographically coherent boundaries for effective data use. ${ }^{40,41}$ By combining clinical understanding, technical ability, and facilitation, the Clinical Effectiveness Group fulfilled a contextually essential role for responsive IT development. Similar examples of IT-enabled learning health systems have developed in the US, including Kaiser Permanente and the Veterans Health Association. ${ }^{42,43}$

\section{Implications for practice}

The networks were viewed as sustainable, and the grouping of all 36 practices into a federated GP Care Group was seen as feasible. This is because the networks were viewed by practices as successful examples of collaborative working, making the transition to an even larger collaborative structure of all 36 practices in a federated GP Care Group seem like a natural next step. This supports a further progression of collaborative working across the CCG. It also protects practices in the face of increasing marketisation and the requirement to bid competitively for contracts. ${ }^{44}$ Alongside the immediate gains of improvements in clinical care, a major function of the Tower Hamlets practice networks was to accelerate a process of primary care service integration, which remains sensitive to the local context. Interviewees recommended this type of approach and felt it would be applicable in other settings. 


\section{REFERENCES}

1. Ham C. Foreword. In: Goodwin N, Dixon A, Poole T, Raleigh V. Improving the quality of care in general practice: report of an independent inquiry commissioned by The King's Fund. London: The King's Fund, 2011: xiii-xiv. http://www.kingsfund.org.uk/publications/improving-quality-care-generalpractice (accessed 9 Aug 2017).

2. Starfield B, Shi L, Macinko J. Contribution of primary care to health systems and health. Milbank Q 2005; 83(3): 457-502.

3. Addicott R, Ham C. Commissioning and funding general practice: making the case for family care networks. London: The King's Fund, 2014.

4. RAND Europe, Ernst \& Young LLP. Prepared for the Department of Health. National evaluation of the Department of the Health's Integrated Care Pilots. Final Report: full version. Cambridge: RAND Europe, 2012. https://www.gov.uk/ government/uploads/system/uploads/attachment_data/file/146775/dh_133127. pdf laccessed 9 Aug 2017).

5. Goodwin N, Smith J, Davies A, et al. Integrated care for patients and populations: improving outcomes by working together. A report to the Department of Health and the NHS Future Forum. London: The King's Fund, Nuffield Trust, 2012.

6. British Medical Association. GP networks and federations. http://bma.org.uk/ practical-support-at-work/gp-practices/gp-networks laccessed 9 Aug 2017).

7. Ferlie E, Fitzgerald L, McGivern G, et al. Networks in health care: a comparative study of their management, impact and performance. London: National Institute for Health Research Service Delivery and Organisation, 2010.

8. Conner M. Developing network-based services in the NHS. Int J Health Care Qual Assur Inc Leadersh Health Serv 2001; 14(6-7): 237-244.

9. Rosen R, Kumpunen S, Curry N, et al. Is bigger better? Lessons for large-scale general practice. London: Nuffield Trust, 2016.

10. Goodwin N, Dixon A, Poole T, Raleigh V. Chapter 2. The evolving role and nature of general practice in England. In: Improving the quality of care in general practice: report of an independent inquiry commissioned by the King's Fund. London: The King's Fund, 2011: 13-24. http://wnw.kingsfund.org.uk/ publications/improving-quality-care-general-practice laccessed 9 Aug 2017).

11. Darzi A. A framework for action. London: Healthcare for London, 2011. http:// www.londonhp.nhs.uk/wp-content/uploads/2011/03/A-Framework-for-Action. pdf laccessed 9 Aug 2017).

12. Lakhani M, Baker M, Field S. The future direction of general practice: a roadmap. London: Royal College of General Practitioners, 2007. http://www. rcgp.org.uk/policy/rcgp-policy-areas/future-direction-of-general-practice-aroadmap.aspx laccessed 9 Aug 2017).

13. Imison C, Williams S, Smith J, Dingwall C. Toolkit to support the development of Primary Care Federations. London: The King's Fund, Hempsons, The Nuffield Trust, The Royal College of General Practitioners; 2010. http://www.rcgp.org.uk/ clinical-and-research/clinical-resources/primary-care-federations-toolkit.aspx laccessed 9 Aug 2017).

14. NHS England. News. Spreading new care models. 2017. https://umw.england. nhs.uk/2017/02/new-care-models/laccessed 15 Aug 2017).

15. NHS England. Integrated care pioneers announced. 2013. http://wnw.england. nhs.uk/2013/11/01/interg-care-pioneers/ laccessed 9 Aug 2017).

16. Ham C, Curry N. Integrated care. What is it? Does it work? What does it mean for the NHS? London: The King's Fund, 2011. http://www.kingsfund.org.uk/ publications/articles/integrated-care-summary-what-it-does-it-work-whatdoes-it-mean-nhs laccessed 9 Aug 2017).

17. Tower Hamlets Council. Borough statistics. http://www.towerhamlets.gov.uk/ lgs//901-950/916_borough_statistics.aspx (accessed 9 Aug 2017).

18. Tower Hamlets Council. Population key facts: a profile of the population of Tower Hamlets. London: Tower Hamlets Council, 2013. http://mww.towerhamlets.gov. uk/Documents/One-TH/Researc-h-Briefing-TH-Population-Key-Facts-2013-12. pdf laccessed 9 Aug 2017).

19. Tower Hamlets Council. Indices of Deprivation 2010. London: Tower Hamlets Council, 2011. http://uww.towerhamlets.gov.uk/Documents/Adult-careservices/Supporting-adults/Health/Indices-of-deprivation-2011.pdf laccessed 9 Aug 2017).

20. NHS Tower Hamlets. Primary care strategic investment plan proposal. London: Tower Hamlets Council, 2009.

21. McKinsey \& Company. Transforming primary care in Tower Hamlets: a story of collaborative success as a precursor to broader integration. London: McKinsey \& Company, 2014

22. Hull S, Chowdhury TA, Mathur R, Robson J. Improving outcomes for patients with type 2 diabetes using general practice networks: a quality improvement project in east London. BMJ Qual Saf 2014; 23(2): 171-176.

23. Robson J, Hull S, Mathur R, Boomla K. Improving cardiovascular disease using managed networks in general practice: an observational study in inner London. Br J Gen Pract 2014; DOl: https://doi.org/10.3399/bjgp14X679697.

24. Cockman P, Dawson L, Mathur R, Hull S. Improving MMR vaccination rates: herd immunity is a realistic goal. BMJ 2011; 343: d5703.

25. Hull S, Mathur R, Lloyd-Owen S, et al. Improving outcomes for people with COPD by developing networks of general practices: evaluation of a quality improvement project in east London. NPJ Prim Care Respir Med 2014; 24: 14082.

26. Pope C, Ziebland S, Mays N. Qualitative research in health care. Analysing qualitative data. BMJ 2000; 320(7227): 114-116.

27. Braun V, Clarke V. Using thematic analysis in psychology. Qual Res Psychol 2006; 3(2): 77-101.

28. Pawa J. MSc project report: An examination of general practice networks in East London. London: LSE, 2015. https://discover.lshtm.ac.uk/primo-explore/ fulldisplay?docid=44HYG_ALMA519896680003736\& context=L\&vid=44HYG_ VU1\&search_scope $=44 \mathrm{HYG} \_A L M A \& t a b=$ default_tab\&lang=en_US laccessed 15 Aug 2017).

29. Bauer MW, Gaskell G, eds. Qualitative researching with text, image and sound: a practical handbook. London: SAGE Publications, 2000.

30. Ziebland S, McPherson A. Making sense of qualitative data analysis: an introduction with illustrations from DIPEx (personal experiences of health and illness). Med Educ 2006; 40(5): 405-414.

31. McKinsey \& Company. Tower Hamlets Networks: governance session 1. London: McKinsey \& Company, 2009.

32. Blizard Institute. Clinical Effectiveness Group. http://uww.blizard.qmul.ac.uk/ ceg-home.html laccessed 9 Aug 2017).

33. Kotter JP. Leading change: why transformation efforts fail. Harvard Business Review 1995; March-April: 59-67.

34. Suter E, Oelke ND, Adair CE, Armitage GD. Ten key principles for successful health systems integration. Healthc Q2009; 13: 16-23.

35. Iles V, Sutherland K. Managing change in the NHS. Organisational change: a review for health care managers, professionals and researchers. London: National Co-ordinating Centre for NHS Service Delivery and Organisation R\&D, 2001.

36. Campbell SM, Sheaff R, Sibbald B, et al. Implementing clinical governance in English primary care groups/trusts: reconciling quality improvement and quality assurance. Qual Saf Health Care 2002; 11(1): 9-14.

37. Sheaff R, Marshall M, Rogers A, et al. Governmentality by network in English primary healthcare. Soc Policy Adm 2004; 38(1): 89-103.

38. van den Hombergh P, Grol R, van den Hoogen HJ, van den Bosch WJ. Practice visits as a tool in quality improvement: acceptance and feasibility. Qual Health Care 1999; 8(3): 167-171.

39. Baskerville NB, Liddy C, Hogg W. Systematic review and meta-analysis of practice facilitation within primary care settings. Ann Fam Med 2012; 10(1): 63-74.

40. de Lusignan S, van Weel C. The use of routinely collected computer data for research in primary care: opportunities and challenges. Fam Pract 2006; 23(2): 253-263.

41. Hann M, Baker D, Hayes J, et al. Methodological issues in the development of a national database for primary care groups and trusts. Health Soc Care Community 2001; 9(5): 286-293.

42. Protti D. Integrated care needs integrated information management and technology. Healthc Q2009; 13: 24-29.

43. McKinsey \& Company. What health systems can learn from Kaiser Permanente: an interview with Hal Wolf. 2009. http://www.mckinsey.com/ industries/healthcare-systems-and-services/our-insights/what-healthsystems-can-learn-from-kaiser-permanente-an-interview-with-hal-wolf (accessed 9 Aug 2017).

44. Hawkes N. Rise of the federation: how GPs are meeting the challenge of competition. BMJ 2014; 348: g2155. 


\section{Appendix 1. Interview topic guide}

\begin{tabular}{|c|c|}
\hline Theme & Topics and probing questions $\mathrm{s}^{\mathrm{a}}$ \\
\hline $\begin{array}{l}\text { Rationale for networks } \\
\text { General/role in } \\
\text { Tower Hamlets }\end{array}$ & $\begin{array}{l}\text { - Tell me a bit about your current role with Tower Hamlets } \\
\text { What are the day-to-day activities that you are involved in? } \\
\text { - And what was your role at the time the networks were developed? } \\
\text { - Could you summarise your role in the development and implementation of the networks? } \\
\text { - Are there any other positions you've held within Tower Hamlets? }\end{array}$ \\
\hline Early planning & $\begin{array}{l}\text { What were some of the challenges the family practices faced in their interactions that prompted or informed early discussions } \\
\text { around the networks? } \\
\text { - Were you involved in the early planning of the initiative? If so, could you describe your role and the role of other key actors? } \\
\text { - Do you have any other insights or thoughts on the early planning and rationale behind the networks? }\end{array}$ \\
\hline $\begin{array}{l}\text { Intended goals/ } \\
\text { Integration }\end{array}$ & $\begin{array}{l}\text {-What were the intended aims of the networks from your point of view? } \\
\text { - What type of project do you feel best describes the networks? For example, quality improvement, integration } \\
\text { - What is your understanding of the term integration? What implications do you think it has for Tower Hamlets? }\end{array}$ \\
\hline $\begin{array}{l}\text { Network components } \\
\text { Components }\end{array}$ & $\begin{array}{l}\text { - What were the key components of the network in your view? } \\
\text { Probing questions (if needed) } \\
\text { - Administrative support } \\
\text { - Education, skills training, developing capacity } \\
\text { - Evidence-based guidelines or care standards (packages) } \\
\text { - Financial incentives } \\
\text { - Information technology (IT) systems } \\
\text { - Outcome measurement (including dashboards) } \\
\text { - Reporting and feedback } \\
\text { - Leadership and peer support (social) } \\
\text { - Aligning norms and values (culture) } \\
\text { - Patient involvement } \\
\text { - Other }\end{array}$ \\
\hline Individual components & $\begin{array}{l}\text { - How were patients involved in this process? } \\
\text { - What role do you feel financial incentives played within the network? } \\
\text { - Large or small role? } \\
\text { - Impact of being collective las a network) } \\
\text { - What role do you feel the network manager played? } \\
\text { - How did the communication and meetings held as part of the network process affect your practice? } \\
\text { - Could you describe how reporting and feedback was done? Do you feel this was used to change practice? } \\
\text { - What are your thoughts on the role of IT systems? } \\
\text { - Do you feel the networks were well resourced financially to achieve their aims? } \\
\text { - There was a considerable financial investment in the networks. In what way was this money used? In what ways was it most helpful? }\end{array}$ \\
\hline Aligning & $\begin{array}{l}\text { - How did the network align with existing initiatives (such as national targets, primary care incentives, and hospital incentives) } \\
\text { and what role do you feel this played? } \\
\text { (For example, Quality and Outcomes Framework, hospital QIPP targets, diabetes national targets 'Year of Care,' national } \\
\text { immunisation targets) } \\
\text { - Is there anything that was not included in the networks programme you feel could or should have been? }\end{array}$ \\
\hline Facilitating factors & $\begin{array}{l}\text { - What factors facilitated adopting the networks? } \\
\text { Probing questions (if needed) } \\
\text { - Peer support } \\
\text { - Leadership } \\
\text { - IT support } \\
\text { - Financial incentives } \\
\text { - Existing structures or relationships within Tower Hamlets? } \\
\text { - Existing national policies or structures? (For example, priority of integration) } \\
\text { - Other } \\
\text { - What factors do you think were indispensable to implementing the networks? }\end{array}$ \\
\hline Barriers & $\begin{array}{l}\text { - What factors hindered adopting the networks? } \\
\text { Probing questions (if needed) } \\
\text { - Professional culture and norms } \\
\text { - Communication difficulties } \\
\text { - IT challenges } \\
\text { - Budget restrictions } \\
\text { - Leadership challenges } \\
\text { - Time restraints }\end{array}$ \\
\hline
\end{tabular}




\section{Appendix 1 continued. Interview topic guide}

- Patient concerns

- Other

- Would you identify finances or budget restrictions as a barrier?

Flexibility and level - How flexible or responsive did you find the development and implementation of the networks?

of implementation - What role do you feel the clinical effectiveness group played in developing the networks? Specifically the clinical leads?

- How did you approach navigating the culture change with this project?

Effects

- Do you feel the networks achieved their intended goals?

- What changes in your work did you notice when the networks were implemented? Increased or decreased breadth, depth, responsibility, level of interest

- Other than the four specific programmes, do you feel the networks have impacted in other areas? If so, which?

Follow-up: What are your thoughts on the network improved services such as for mental illness and sexual health?

- What do you feel the impact of the networks on patients has been?

- Recognising that practices may serve different patient populations, what challenges did this present and how do you feel yourself and your colleagues responded to these challenges?

Potential follow-up: how do you feel setting up the networks based on geographical boundaries differed from the model applied with fundholding?

- Similarly, practices also vary in size - what impact do you feel this had on the process?

- What are three of the most important things you think have changed through the process of the networks?

- What are your thoughts on the sustainability of the networks? Potential probes:

- Do you feel changes have been embedded in routine practice?

- Long-term financial viability

- What are some of the key lessons you feel have been learned through the networks?

Other - What do you feel is likely to happen with the networks in the future?

Potential follow-up: What unfinished work or next steps would you identify with respect to the networks?

- Do you feel the networks could be applied to other GP practices either in the UK or in other countries?

(Or do you feel what was implemented was very context-specific to Tower Hamlets?]

- Have you been asked or are you aware of individuals in Tower Hamlets being asked about their experience with networks in Tower

Hamlets in order to learn from it or apply it to their own context?

- Are there any particular individuals you would identify as leaders with this project - either at a local level or with the various

organisations involved?

- Is there anyone else you would suggest that would be helpful to interview for this project?

Conclusion - Is there anything else you would like to add?

Closing - Summarise

- Thank you very much for your time

- Ensure have contact information for any questions

${ }^{3}$ Core or key questions are in bold. 